\title{
Research on the relationship between social network sites use and employee well-being based on cross-sectional data by structural equation modeling
}

\author{
Weishan Luo ${ }^{1}$, Ying Jiang ${ }^{2}$, Huachun Zeng ${ }^{3}, \mathrm{He} \mathrm{Lin}^{4}$, and Guobin DaiRen ${ }^{5^{*}}$ \\ ${ }^{1}$ Biquan Academy, Xiangtan University, Xiangtan, China \\ 2-5 Business School, Central South University, Changsha, China
}

\begin{abstract}
With the rapid rise of social network sites, people's life and work are influenced to varying degrees. And this paper aims to explore how does social network sites use(SNSU) affect employee well-being(EWB) and the mediating effects of body image disturbance(BID) and self-esteem(SE). Social network sites use, employee well-being, body image disturbance and self-esteem scales were used to obtain data of 435 employees. Results showed that social network sites use positively predicted employee well-being; Selfesteem played a mediating role in the relationship between social network sites use and employee well-being, but the mediation of body image disturbance and the chain mediation of body image disturbance and selfesteem weren't significant. So social network sites use can lead to body image disturbance to some extent but overall, its impact was positive, which was contributing to employee well-being.
\end{abstract}

\section{Introduction}

According to iiMedia Research data, the scale of China's mobile social users exceeds 900 million in 2020, which means that SNSU has basically become a daily necessity. Social network sites are new products in the Internet era, and their influence has penetrated all aspects of people's lives and work. Employees make extensive use of social network sites through computers, mobile phones, iPads and other devices in work and non-work situations. Based on this, more and more scholars have turned their research interest to the use of social network sites. For example, in recent years, the impact of SNSU on well-being has attracted much attention[1].

Well-being has always been the wonderful experience that humans dream of[2]. EWB is not only the subjective experience of employees, but also vital to the survival and development of organizations [3]. Previous studies have shown that EWB not only helps to improve individual performance[4], but also has a positive impact on organizational performance[5]. Therefore, it is a valuable research issue to explore the relationship between SNSU and EWB, which helps to improve EWB and so as to achieve a win-win situation for employees and organizations.

\section{Hypothesis development}

Social network sites refers to online platforms which allow users to create and share visual and textual content with other users[1]. Past studies have pointed out that employees using social network sites will be more satisfied with the work environment $[6,7]$. When the external environment meets the individual's psychological needs, the individual can grow and gain happiness[8]. Therefore, Hypothesis 1: SNSU positively predicts EWB.

Studies have shown that traditional media are related to $\operatorname{BID}[9,10]$. Considering the similarities between social network sites and traditional media, SNSU may result in negative body image. According to social comparison theory[11], people always tend to compare with people who are "similar to themselves". A meta-analysis study showed that SNSU is positively associated with BID[12]. Therefore, this article proposes Hypothesis 2: BID plays a mediating role in the relationship between SNSU and EWB.

Individuals with a high degree of BID have excessively distorted negative perceptions of their bodies and believe that it will affect other aspects of their lives, which may reduce their SE. Research showed that adolescents with negative body image have lower levels of SE[13].

Self-esteem is defined as the subjective evaluation of one's own value and reflects people's confidence in their abilities, importance, value and sense of success [14]. It is one of the most reliable and powerful predictors of happiness[14]. Previous studies have shown that decline of SE is a precursor to a series of psychological problems, such as anxiety[15], depression[16]. SE has also been proved to mediate the relationship between online social comparison and depressive symptoms[16]. Upward social comparison is likely to hurt SE and well-being [17]. Therefore, this article proposes Hypothesis 3: SE plays a mediating role between SNSU and EWB; and Hypothesis

*daiguobin@csu.edu.cn 
4: BID and SE play a chain mediating role between SNSU and EWB.

\section{Method}

\subsection{Participants}

Convenient sampling method was used to conduct the questionnaire survey and 435 questionnaires were obtained, of which the number of valid questionnaires was 416 and the effectiveness was $95.63 \%$.

\subsection{Measurements}

In this study, the measures assessing these constructs are all mature scales.

- The active-passive social network sites use. The scale developed by Tandoc et al[18] comprises 7 items rated from $1=$ never to $5=$ always. Scores on this scale have shown internal consistency in college students samples[18]. Cronbach's Alpha in the current sample was 0.86 .

- Body Image Disturbance. The Body image disturbance questionnaire[19] comprises 7 items rated from $1=$ not at all concerned to $5=$ extremely concerned. Scores on the BIDQ have shown internal consistency and construct validity among public university students in the United
States[19]. In this study, the Cronbach's Alpha was 0.93 .

- $\quad$ Self-esteem. The Rosenberg self-esteem scale in Chinese version[20] contains 10 items rated from $1=$ strongly disagree to $4=$ strongly agree. Research has shown that the eighth item in RSE is not appropriate for Chinese people[21], so it is recommended to delete this item. Scores on the RSE have shown internal consistency and construct validity among undergraduate students[22]. In this study, the Cronbach's Alpha was 0.86 .

- $\quad$ Employee well-being. The employee well-being scale[23] contains 18 items rated from $1=$ strongly disagree to $5=$ strongly agree, with higher scores reflecting higher level of EWB. Scores on the EWB have shown internal consistency, convergent validity and discriminant validity among employees in Beijing[23]. In this study, Cronbach's Alphas were 0.97 .

\section{Results}

\subsection{Descriptive Statistics}

Tab 1 lists the means, standard deviations of SNSU, SE, BID, EWB, and correlations between these variables.All correlations were in the expected directions, supporting subsequent hypotheses testing.

Table1. Means, Standard Deviations, and Correlations between Variables.

\begin{tabular}{|c|c|c|c|c|c|c|}
\hline & SNSU & BID & SE & EWB & gender & age \\
\hline SNSU & 1.00 & & & & & \\
\hline BID & $0.12^{* \mathrm{a}}$ & 1.00 & & & & \\
\hline SE & $0.16^{* * a}$ & $-0.30 * *$ & 1.00 & & & \\
\hline EWB & $0.35 * *$ & -0.08 & $0.50 * *$ & 1.00 & & \\
\hline gender & -0.08 & 0.01 & 0.02 & 0.04 & 1.00 & \\
\hline age & -0.09 & $-0.16^{* *}$ & $0.18 * *$ & $0.15^{* *}$ & $0.14^{* *}$ & 1.00 \\
\hline M & 3.06 & 2.70 & 2.92 & 3.41 & 0.46 & 26.51 \\
\hline
\end{tabular}

${ }^{\text {a }} \mathrm{N}=415 ;{ }^{*} \mathrm{p}<0.05, * * \mathrm{p}<0.01$ (two-tailed).

\subsection{Common Method Variance}

Harman's single factor test was used to test the common method variance. The result showed that there were 9 factors with eigenvalues greater than 1 , and the explanatory value of the first factor was $33.3 \%$, less than the critical standard of $40 \%$, indicating that there was no serious common method variance in this study.

\subsection{Test of The Structural Model}

The theoretical model showed a good fit to the data $(\chi 2 / \mathrm{df}=2.8, \mathrm{p}<0.001, \mathrm{CFI}=0.97 \mathrm{IFI}=0.97, \mathrm{RMSEA}=0.066$ $\mathrm{RSMR}=0.049)$. As the results shown, SNSU was positively associated with $\mathrm{BID}, \beta=0.12, \mathrm{p}<0.05$, and SE, $\beta=0.28, p<0.001$ as expected. Meanwhile, the direct pathway from SNSU to EWB was positive and significant. The negative pathway from BID to $\mathrm{SE}, \beta=0.12, \mathrm{p}<0.001$, was significant, but the pathway from BID to EWB, $\beta$ $=0.05, p=0.24$, was non-significant, which was different from the study expected. Furthermore, SE was positively correlated with EWB, $\beta=0.51, p<0.001$. In summary, 
except for the pathway from BID to EWB, the relationship between these constructs was basically the same as expected.

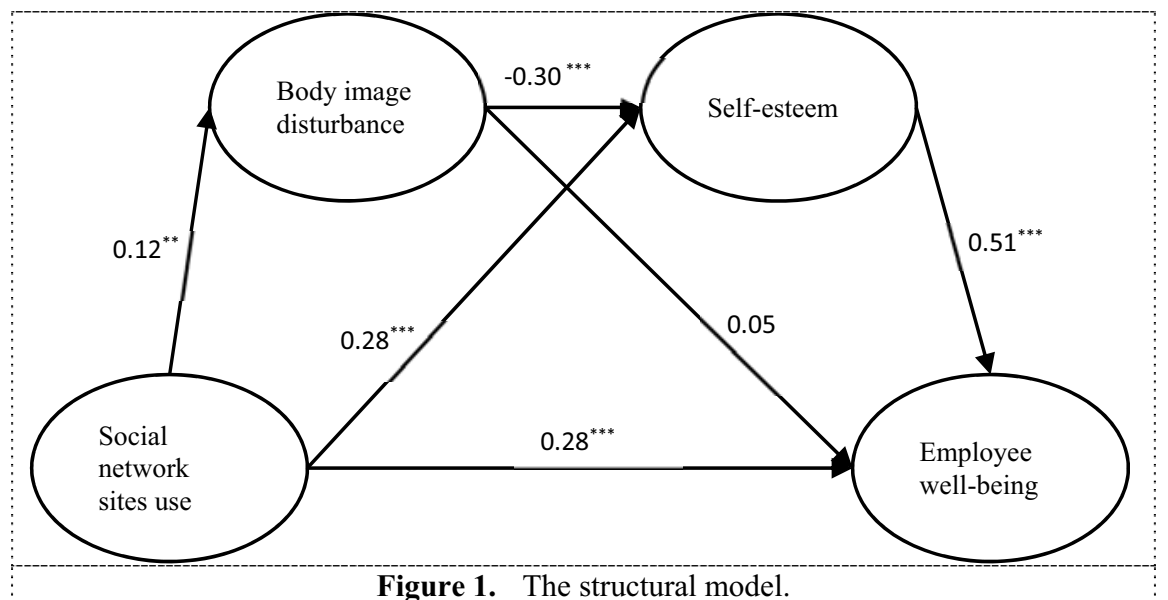

Table2. Path Coefficients of the structural model.

\begin{tabular}{ccccc}
\hline & $\beta$ & S.E & C.R & P \\
\cline { 2 - 5 } SNSU $\rightarrow$ BID & 0.116 & 0.053 & 2.191 & .028 \\
BID $\rightarrow$ SE & -0.302 & 0.035 & -5.82 & $* * * a$ \\
SNSU $\rightarrow$ SE & 0.282 & 0.035 & 5.326 & $* * *$ \\
SE $\rightarrow$ EWB & 0.511 & 0.077 & 9.784 & $* * *$ \\
SNSU $\rightarrow$ EWB & 0.281 & 0.047 & 5.869 & $* * *$ \\
BID $\rightarrow$ EWB & 0.053 & 0.045 & 1.173 & .241 \\
\hline
\end{tabular}

${ }^{\mathrm{a}} \mathrm{N}=415 ; * * * \mathrm{p}<0.001$.

\subsection{Test of the Mediation}

The bias-corrected Bootstrap method was used to test the mediation effect. First, as the Tab 3 shown, the total effect of SNSU to EWB was positive and significant, $\beta=0.413$, $\mathrm{p}<0.001,95 \%$ CI $[0.273 ; 0.544]$, supporting H1.The indirect effects of SNSU on EWB via BID, $\beta=0.006$, $p$ $=0.021,95 \% \mathrm{CI}[-0.005 ; 0.033]$, was non-significant, but via SE was significant, $\beta=0.144, \mathrm{p}<0.001,95 \%$ CI
[0.083; 0.214], which disconfirms H2 but supports H3. Furthermore, the indirect effect of SNSU on EWB via BID and SE (chain mediation) was negative but non-significant, $\beta=0-.018, p=0.08,95 \%$ CI [-0.045; 0.003], so H4 wasn't supported. It can be speculated that the non-significant chain mediation may be due to that SNSU has a stronger positive effect on SE, covering the negative effect transmitted by BID.

Table3. Results of mediation test

\begin{tabular}{ccccccc}
\hline & Indirect/Total & $\beta$ & S.E & ULCI & LLCI & P \\
\cline { 2 - 6 } & BID & 0.006 & 0.008 & -0.005 & 0.033 & 0.211 \\
SNSU $\rightarrow$ EWB & SE & 0.144 & 0.033 & 0.083 & 0.214 & $* * *$ \\
& BID \& SE & -0.018 & 0.012 & -0.045 & 0.003 & 0.080 \\
& Total & 0.413 & 0.069 & 0.273 & 0.544 & $* * *$ \\
\hline
\end{tabular}

\section{Discussion}

The research showed that SNSU promotes EWB, which is somewhat different from the research conclusion of Priyadarshini et al[24]. This may be because the samples in this study were taken during the COVID-19 outbreak. During this period, it is common for employees to work at home and online. The use of social network sites provides an effective communication environment for employees to work normally. Well-being is not only a personal instant emotional experience, but also the realization of personal value. And employees' dedication to work will help realize their personal values and thus improve their well-being. Although this research was sampled in a special period, the results of the study still illustrate the value of SNSU to employees and even companies. Therefore, people should take an objective view of the new social and work patterns in the Internet era and make full use of the valuable aspects of social network sites.

With the advent of the Internet era, the use of social network sites has penetrated into all aspects of our lives. It is very valuable to give full play to the positive role of 
social network sites and improve EWB. For example, managers can positively guide employees to evaluate themselves objectively, and not over-compare with the "friends" in the social network sites, so as not to cause BID. In addition, since the samples in this article were taken during the COVID-19 pandemic period, whether there is the same conclusion during the non-epidemic period remains to be tested by future studies. Future studies can conduct in-depth research on the relationship and mechanism of social network sites and EWB.

\section{Acknowledgments}

Financial Disclosure This study is partially supported by the Chinese National Social Science Fund 15BGL104. The views represented in this article are those of the individual authors only.

\section{References}

1. Kaplan, A. M , Haenlein, et al. (2010) Users of the world, unite! The challenges and opportunities of Social Media. Business Horizons Bloomington. .

2. Cao, M., Xi, M., Zhao, S.M. (2019) The impact of high-performance work systems on employee wellbeing: a cross-level model based on selfdetermination theory. Nankai Business Review. 22(02): 178-187.

3. Spreitzer, G., Porath,C. (2012) Creating sustainable performance, Harv Bus Rev. 90(1-2): 92-99.

4. Pagán-Castao, E., Maseda-Moreno, A. and SantosRojo, C. (2020) Wellbeing in work environments. Journal of Business Research. 115.

5. Huettermann, H., Bruch, H. (2019) Mutual Gains? Health-Related HRM, Collective Well-Being and Organizational Performance. Journal of Management Studies. 56(6): 1045-1072.

6. Koch, H., Gonzalez, E., Leidner, D. (2012) Bridging the work/social divide: the emotional response to organizational social networking sites. European Journal of Information Systems, 21(6): 699-717.

7. Zhang, X., et al. (2015) From e-learning to sociallearning: Mapping development of studies on social media-supported knowledge management. Computers in Human Behavior, 51(OCT.): 803-811.

8. Ryan, R.M., (1995) Psychological needs and the facilitation of integrative processes. Journal of personality. 63(3): 397.

9. Barlett, C.P., Vowels, C.L., Saucier, D.A. (2008) Meta-Analyses of the Effects of Media Images on Men's Body-image Concerns. journal of social \& clinical psychology, 27(3): 279-310.

10. Grabe, S., Ward, L.M., Hyde, J.S. (2008) The role of the media in body image concerns among women: a meta-analysis of experimental and correlational studies. Psychological Bulletin. 134(3): 460-476.
11. Festinger, L.A., (1954) A Theory of Social Comparison Processes. Human Relations. 7(2): 117140.

12. Saiphoo, A.N., Vahedi, Z. (2019) A meta-analytic review of the relationship between social media use and body image disturbance. Computers in Human Behavior.

13. Dailin, Z., et al., (2017) The relationship between adolescent body image and anxiety and depression: the mediating role of self-esteem. Chinese Journal of Clinical Psychology. (5).

14. Chunhan, G., (2019) The relationship between selfcenteredness and subjective well-being of college students: the mediating role of self-esteem. Psychological and behavioral studies. 17(04): 546552.

15. Yali, Z., Sen, L., Yu, G.L. (2019) The relationship between self-esteem and social anxiety: a metaanalysis based on the Chinese student population. Advances in Psychological Science. 27(06): 10051018.

16. Gengfeng, N., et al. (2016) The influence of Qzonebased use of social networking sites on adolescent depression: the serial mediating role of upward social comparison and self-esteem. Acta Psychologica Sinica, 48(10): 1282-1291.

17. Schmuck, D., et al., (2019) "Looking Up and Feeling Down" The Influence of Mobile Social Networking Site Use on Upward Social Comparison, Self-Esteem, and Well-Being of Adult Smartphone Users. Telematics and Informatics. 42(SEP.): 101-240.

18. Tandoc, E.C., Ferrucci, P., Duffy, M. (2015) Facebook use, envy, and depression among college students: Is facebooking depressing?. Computers in Human Behavior. 43(feb.): 139-146.

19. Cash, T.F. (2004) Measuring "negative body image": validation of the Body Image Disturbance Questionnaire in a nonclinical population. Body Image. 1(4): 363-372.

20. Wang, X.D., Wang, X.D., Ma, H. (1999) Mental Health Rating Scale Manual. Chinese Journal of Mental Health, Beijing.

21. Chen, C., Ting,Y. (2012) The relationship between college students' perfectionism, self-esteem and academic procrastination. In: The 15th National Conference on Psychology.

22. Robins, R.W., Hendin, H.M., Trzesniewski, K.H. (2016) Measuring Global Self-Esteem: Construct Validation of a Single-Item Measure and the Rosenberg Self-Esteem Scale. Personality and Social Psychology Bulletin. 27(2): 151-161.

23. Zheng, et al., (2015) Employee well-being in organizations: Theoretical model, scale development, and cross-cultural validation. Journal of Organizational Behavior. 36: 621

24. Priyadarshini, C., et al., (2020) Impact of a Social Media Addiction on Employees' Wellbeing and Work Productivity. The Qualitative Report. 25. 